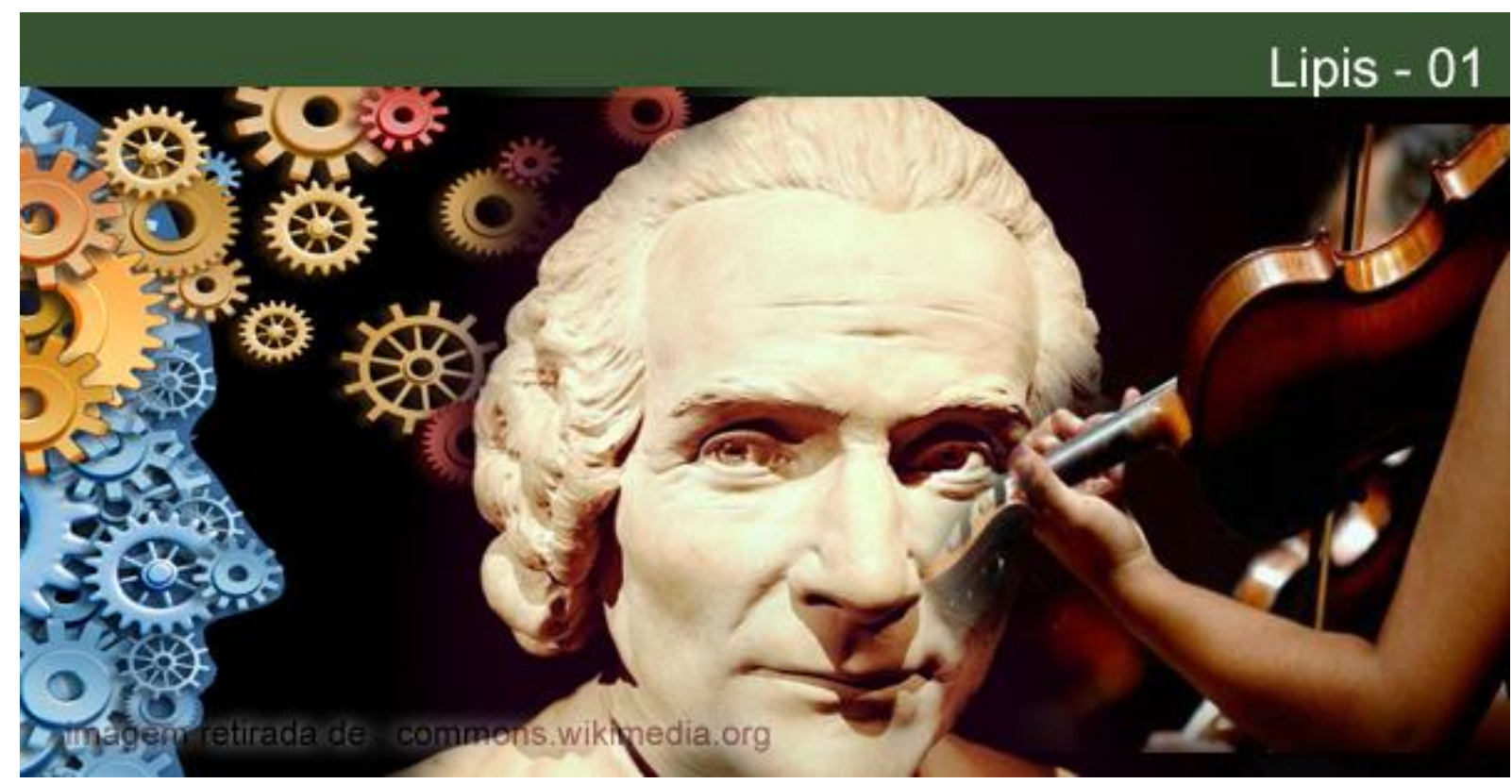

\title{
ROUSSEAU E A LINGUAGEM MUSICAL: O ENSAIO SOBRE A ORIGEM DAS LÍNGUAS
}

\section{Rafael Lima dos Santos}

Mestre em Psicologia pela Pontifícia Universidade Católica (PUC-Rio). Membro do Departamento de Psicologia - Programa de Pós-Graduação em Psicologia Clínica da PUC-Rio.E-mail: herrlima1981@gmail.com.

\section{Luciana Fontes Pessôa}

Pós-Doutorado na área de Psicologia do Desenvolvimento na Universidade do Estado do Rio de Janeiro (UERJ). Doutora e Mestre em Psicologia Social pela UERJ. Professora do Departamento de Psicologia - Programa de Pós-Graduação em Psicologia Clínica da Pontifícia Universidade Católica do Rio de Janeiro (PUC-Rio). E-mail: pessoalf@gmail.com.

Resumo: O presente trabalho visa fomentar as discussões a respeito da comunicação humana, compreendida em sua riqueza de multiplicidade e diversidade que vai além do signo linguístico. Para tanto, tem por objetivo estabelecer paralelos entre as linguagens verbal e musical, analisando criticamente um pouco da natureza de ambas a partir de uma visão inovadora e original presente no Ensaio sobre a origem das línguas de Rousseau. Nessa obra, o autor se propõe repensar a compreensão evolutiva da humanidade tendo a linguagem como condutora de tal evolução - e não os tradicionais e datados marcos históricos. Rousseau defende ser a música o paradigma da perfeita expressão - expressão essa que, ao longo do tempo, foi perdida em detrimento da clareza e da objetividade comunicativas. Com as proposições teóricas elencadas no presente artigo, diferenças e similitudes entre verbal e musical são expostas para um maior entendimento das implicações de atuação da prática musical no que diz respeito às suas possibilidades e potencialidades tanto de atuação quanto de alcance.

Palavras-chave: Linguagem. Música. Comunicação.

\section{ROUSSEAU AND THE MUSICAL LANGUAGE: ESSAY ON THE ORIGIN OF THE LANGUAGES}

Abstract: The present work aims to foment the discussions about human communication, understood in its wealth of multiplicity and diversity that goes beyond the linguistic sign. To do so, it aims to establish parallels between verbal and musical languages, analyzing critically some of the nature of both from an innovative and original vision present in the Essay on the origin of the languages of Rousseau. In this work, the author proposes to rethink the evolutionary understanding of humanity having language as the conduit of such evolution - and not the

\section{POLÊM!CA $\mid$ LABORE (3)}

Polêmica - Revista Eletrônica da Uerj - Rua São Francisco Xavier, 524, $1^{\circ}$ andar bloco D, sl.1001 • Tels.: +55 21 2334-4088 / 4087 • http://www.e-publicacoes.uerj.br/index.php/polemica/index http://www.labore.uerj.br • laboreuerj@yahoo.com.br 
traditional and dated historical landmarks. Rousseau argues that music is the paradigm of perfect expression - an expression that, over time, has been lost to the detriment of communicative clarity and objectivity. With the theoretical propositions mentioned in this article, differences and similarities between verbal and musical are exposed to a greater understanding of the implications of the performance of musical practice with respect to its possibilities and potentialities both in performance and scope.

Keywords: Language. Music. Communication.

\section{(Re)Pensando a linguagem}

Para além da clássica díade saussureana significado $x$ significante como definidora do signo linguístico, inscrita no exercício dinâmico das línguas pela fala em si e por seu registro, outras possibilidades são requisitadas quando se pretende um entendimento mais abrangente do multifacetado espectro da produção humana de significação.

Porque linguagem é boca, olhos e ouvidos, mas também é mãos, nariz, pele - bem como aquilo cuja conceituação pode ser vaga e imprecisa, embora, de alguma maneira, certa: intuição, insight, percepção, o espaço-entre e tudo o que não se inscreve no império imagético do olhar ou não pode ser definido por palavras.

$\mathrm{Na}$ eterna busca de sentidos, afetamos e somos afetados não apenas pelo que falamos ou ouvimos ou lemos ou escrevemos. Podemos ser impelidos igualmente por um toque, um aroma, uma impressão que sequer possua materialidade concreta, embora, pura e simplesmente, comunique - não mencionando aquilo que se escuta no não-dito, o que é ouvido no silêncio dos diálogos, o que é lido e percebido nas entrelinhas dos discursos.

O que permite, necessariamente, que o entendimento da linguagem seja mais que a convenção determinante do signo, nesse desconhecido da caminhada que, ao sabor de Drão (GIL, 1982), tornam essa estrada verdadeira "caminhadura". Com toda ação, energia, entrega, conquista, interesse e fascínio - assim como também perigo, apreensão, dúvida, incerteza.

No que diz respeito à comunicação, pode-se pensar a música como uma saída possível quando as palavras faltam, inexistem ou simplesmente não dão conta de expressar um estado emocional que, ainda assim, precisa ser expresso. É quando, por exemplo, uma canção nos arrebata sem que saibamos explicar o porquê - ao menos, não com palavras.

E é nesse sentido que Rousseau, em seu Ensaio sobre a origem das línguas, tem original contribuição para o entendimento da comunicação humana. Esse texto inova por instaurar na corrente de estudos linguísticos e sociológicos a possibilidade de pensar, partindo da linguagem, a própria história da humanidade. Ponderando com mestria acerca da natureza das línguas, o pensador iluminista vê na música o paradigma da perfeita expressão.

\section{POLÊM!CA $\mid$ LABORE}

Polêmica - Revista Eletrônica da Uerj - Rua São Francisco Xavier, 524, $1^{\circ}$ andar bloco D, sl.1001 • Tels.: +55 21 2334-4088 / 4087 • http://www.e-publicacoes.uerj.br/index.php/polemica/index http://www.labore.uerj.br • laboreuerj@yahoo.com.br 


\section{Algumas linhas conceituais sobre a linguagem}

O gramático Bechara (2009), em sua definição de linguagem, admite que "não falamos só com as unidades linguísticas", participando desse processo “a mímica, a entonação, o ritmo, as pausas e silêncios, os gestos, os recursos gráficos e outros" (p. 30).

Sendo a materialidade da capacidade humana de representação da realidade (BOCK et al., 2001), a linguagem se inscreve na estrutura social da história dos homens, atribuindo sentido à sua existência, ao seu estar-no-mundo. Ao mesmo tempo, compreendendo os sentidos préexistentes e produzindo novos sentidos: seu "princípio interior de proliferação" mencionado por Foucault (1999, p. 55).

Da Torre de Babel (Gênesis Cap. 11, 1-9) (BÍBLIA, 2003) - explicando miticamente a origem e diversificação das línguas - à imprensa de Gutenberg - disseminando a escrita e, por isso mesmo, exigindo dela uma padronização e sistematização crescentes (RODRIGUES, 2012); das pinturas rupestres ainda hoje expressivas à complexidade orgânica dos hieróglifos; do alfabeto fenício às expressões algébricas nas quais $x, y, z$ já não são mais letras, mas assumem valores os mais diversos: tudo passa pelo humano desejo de comunicar.

Porém, de forma sistemática, os primeiros rudimentos de pressupostos teóricos acerca da linguagem que nos chegaram como tal remontam aos gregos (NEVES, 2005). Não parece exagero supor que, basicamente, tudo o que veio depois deve algo ao Crátilo ${ }^{1}$ de Platão e/ou à Retórica ${ }^{2}$ de Aristóteles. Por outro lado, os ditos pré-socráticos, em sua maioria, estavam às voltas com a explicação sobre a natureza da matéria. Sua dialética era eminentemente voltada para o mundo da physis, da formação e ordenamento das coisas, daquilo que configura o que percebemos com os sentidos.

A partir da sistematização iniciada pelos gregos, a linguagem ganhou dimensões que o presente artigo não tem a pretensão de abordar. Não é propósito retratar aqui, ainda que em linhas gerais, o percurso histórico dos estudos de linguagem - é esse o momento em que Rousseau tem muito mais a dizer, e de maneira muito mais sedutora e original.

\footnotetext{
${ }^{1}$ Diálogo em cujo desenrolar Sócrates é questionado a respeito da possibilidade de relação intrínseca entre as coisas e seus nomes.

${ }^{2}$ Obra que, em linhas gerais, versa sobre a arte de se fazer ouvir.
}

\section{POLÊM!CA | LABORE.}

Polêmica - Revista Eletrônica da Uerj - Rua São Francisco Xavier, 524, $1^{\circ}$ andar bloco D, sl.1001 • Tels.: +55 21 2334-4088/4087 • http://www.e-publicacoes.uerj.br/index.php/polemica/index http://www.labore.uerj.br • laboreuerj@yahoo.com.br 


\section{Rousseau: um iluminista musical}

Jean-Jacques Rousseau (1712-1778), em sua ampla e variada obra, também dedica lugar especial à linguagem. No Discurso sobre a origem e os fundamentos da desigualdade entre os homens (1754/1999) pode-se ler: "o primeiro que, tendo cercado um terreno, atreveu-se a dizer: Isto é meu, e encontrou pessoas simples o suficiente para acreditar nele, foi o verdadeiro fundador da sociedade civil” (ROUSSEAU, 1754/1999, p. 203).

É dado o fio de Ariadne que, em sua labiríntica e densa escrita, não permite que nem autor, nem leitor percam o foco: a linguagem, em sua primeira manifestação fundadora da sociedade, também instaura em sua dinâmica, além da comunicação e da difusão do conhecimento, a desigualdade e a servidão. Bem entendido, pela mesma via de acesso da palavra, a "primeira instituição social" (ROUSSEAU, 1781/2008, p. 97), temos as leis, as normas, as convenções sociais.

Embora soe algo desnecessário falar sobre uma das figuras mais proeminentes e emblemáticas do pensamento iluminista, é preciso admitir que, em verdade, parecem ser poucos os que conhecem as múltiplas faces do autor de Do Contrato Social (1762/2013) possivelmente sua mais difundida obra, publicada em 1762. Muito poucos são os que sabem, por exemplo, que Rousseau também foi romancista, botânico, crítico, libretista e músico autodidata - tendo composto, inclusive, obras para instrumentos solistas, peças vocais e óperas.

Desde o Emílio (1762/2004) ao Ensaio sobre a origem das línguas (1781/2008), percebemos a música presente em sua obra. Sua primeira publicação, inclusive, foi uma Dissertação sobre a música moderna (1743/1995), além de ter sido autor de um Dicionário de música (1768, 1772, 1775, 1826/1995) e de um Tratado sobre a música (1782/1995). Para Rousseau, portanto, a música é parte de sua escrita, parte de sua vivência e de sua obra.

No Ensaio, Rousseau (1781/2008) confronta diretamente a tradição logocêntrica da Filologia clássica de então. E isso porque, para além da grande questão "como nasceu a linguagem", a leitura da obra deixa claro que formulações outras parecem ser mais intrigantes: “como a linguagem se tornou o que é hoje?", “como as línguas tal como a conhecemos se tornaram necessárias?”, "por que, em seu processo de gramaticalização, as línguas ficaram esvaziadas de sentido?", “por que aceitar que a palavra é o cerne de toda linguagem?” O interesse maior do autor, portanto, reside na proposta de repensar com originalidade o já estabelecido.

\section{POLÊM!CA $\mid$ LABORE}

Polêmica - Revista Eletrônica da Uerj - Rua São Francisco Xavier, 524, $1^{\circ}$ andar bloco D, sl.1001 • Tels.: +55 21 2334-4088 / 4087 • http://www.e-publicacoes.uerj.br/index.php/polemica/index http://www.labore.uerj.br • laboreuerj@yahoo.com.br 
De acordo com Falabretti (2011, p. 174), a obra em questão

rompe com a lógica das descrições lineares e cronológicas ao utilizar a narrativa do desenvolvimento da linguagem como elemento de sentido da história. No Ensaio, Rousseau descreve uma cadeia de processos evolutivos que comandam a passagem da primeira língua para uma fala articulada até a invenção da escrita, como sendo parte de um mesmo processo de transformação que instaurou a desigualdade e usurpou a liberdade.

Assim como no Emílio - ou Da educação (1762/2004), obra que evidencia como a música é parte do desenvolvimento pleno de um ser humano que se quer "de acordo com a natureza", no Ensaio (1781/2008) temos o mesmo fio condutor, ainda que em outras proporções: a importância que se atribui ao entendimento de algumas proposições defendidas pelo autor diz respeito ao fato de encarar o próprio sentido musical como condutor da História.

Se é verdadeiro o que diz Freitas (2008, p. 3), que "a arte musical surge no pensamento de Rousseau como condição essencial para a restauração da plena comunicação; ela não se restringe a proporcionar o prazer", a música em seu viés terapêutico, por exemplo, encontra paralelo seguro em sua própria dinâmica de atuação, uma vez que entram em jogo as histórias dos sujeitos envolvidos no processo que se quer expressivo de comunicar.

\section{O Ensaio sobre a origem das línguas}

O Ensaio é controverso quanto à data exata de publicação e quanto à "importância que lhe atribuía o autor" (FAVERI, 2001, p. 266). Obra póstuma, parece ter permanecido há muito na sombra de obras outras mais conhecidas como o Discurso sobre a origem e os fundamentos das desigualdades entre os homens (1755/1999) e Do contrato social (1762/2013).

O "cenário" filológico-linguístico em que nasceu o Ensaio ainda era tradicional e fortemente moldado pela perspectiva aristotélica do signo. Em sua Política, Aristóteles (1997) defende o uso do logos (palavra) como particularidade humana, enunciando e significando o bem e o mal, o justo e o injusto, entre outros valores.

Assim, quando aborda valores, Aristóteles deixa clara a relação entre linguagem como acesso e instrumentalização da moralidade mesma. No entanto, segundo Valle (2011, p. 5), “em Rousseau, o liame entre sensação e moralidade é, ao contrário, assegurado pela palavra-música, linguagem expressiva que, superando a mecânica instrumentalidade, faz ressoar os afetos”.

O livro é dividido em pequenos capítulos nos quais o autor narra, de maneira bastante poética, sua teoria a respeito da origem da civilização. Fugindo de uma linearidade clássica e já

\section{POLÊM!CA $\mid$ LABORE}

Polêmica - Revista Eletrônica da Uerj - Rua São Francisco Xavier, 524, $1^{\circ}$ andar bloco D, sl.1001 • Tels.: +55 21 2334-4088 / 4087 • http://www.e-publicacoes.uerj.br/index.php/polemica/index http://www.labore.uerj.br • laboreuerj@yahoo.com.br 
consolidada baseada, sobretudo, nos feitos humanos, Rousseau (1781/2008) se propõe recontar a história da humanidade pelo viés da linguagem - não é propósito aqui discorrer a respeito de todo o Ensaio, mas se faz necessário um breve mapeamento de algumas partes representativas para um maior entendimento global da obra.

Nos três primeiros capítulos, Rousseau (1781/2008) fala das diferenças entre a linguagem visual e a linguagem discursiva. A visual é a do movimento, do gesto, da comunicação imediata e puramente informativa das necessidades físicas; a discursiva é a sonora, da comunicação capaz de emocionar, de tocar e (co)mover. Os "sentidos" do movimento e da voz, portanto, como iniciadores do processo do reconhecimento da "necessidade de comunicar os próprios sentimentos e os próprios pensamentos" (ROUSSEAU, 1781/2008, p. 97). As paixões teriam sido responsáveis pelo nascimento das línguas, moduladas por acentos expressivos que "mentem menos" a respeito das reais intenções do enunciante. De acordo com Rousseau:

\footnotetext{
Não se começou por raciocinar, mas por sentir. Pretende-se que os homens tenham inventado a palavra para expressar suas necessidades: essa opinião parece-me insustentável. [...] Todas as paixões aproximam os homens, forçados a se separarem pela necessidade de procurar os meios de vida. Não foi a fome nem a sede, mas o amor, o ódio, a piedade, a cólera que lhes arrancaram as primeiras vozes. Os frutos não fogem de nossas mãos, deles é possível alimentar-se sem falar; persegue-se em silêncio a presa que se quer comer: porém, para comover um jovem coração, para repelir um agressor injusto, a natureza dita acentos, gritos, lamentos. Eis as mais antigas palavras inventadas e eis por que as primeiras línguas foram cantantes e apaixonadas antes de serem simples e metódicas (ROUSSEAU, 1781/2008, p. 103104).
}

Assim como na música, a comunicação expressiva dessa proto-língua-cantada não teria a finalidade unívoca de informar; ela também expressa sentimentos mais diversos: a aparição da língua, portanto, pelo desejo. Rousseau (1781/2008), mais além, defende o quanto empobrecemos nossa expressão comunicativa em detrimento da clareza e da objetividade de uma gramaticalização comunicativa massificada.

No quarto capítulo, há uma definição importante de acento, conceito caro dentro da concepção da obra: o acento configura um movimento duplo entre música e língua, caracterizando, segundo Prado Junior (2008, p. 55), uma "gênese única, uma mesma estrutura". A comunicação das primeiras línguas não era articulada (campo da representação, portanto, da convenção), mas acontecia pela modulação das vogais: "Em todas as línguas, as exclamações mais vivas são inarticuladas; os gritos, os gemidos, são simples vogais” (PRADO JUNIOR,

\section{POLÊM!CA $\mid$ LABORE}

Polêmica - Revista Eletrônica da Uerj - Rua São Francisco Xavier, 524, $1^{\circ}$ andar bloco D, sl.1001 • Tels.: +55 21 2334-4088/4087 • http://www.e-publicacoes.uerj.br/index.php/polemica/index http://www.labore.uerj.br • laboreuerj@yahoo.com.br 
2008, p. 107). É quando, pelos sons imitativos do mundo sensível, as onomatopeias se configuram como "imagem" mais representativa dessa proto-língua-música.

No quinto capítulo do Ensaio, entra em cena a escrita. Discorrendo sobre os caminhos da escrita em diferentes culturas, Rousseau (2008) não só advoga que "a arte de escrever não decorre da arte de falar" (p. 113), como também que os conceitos de civilização e evolução não apresentam uma relação de inescapável causalidade com a história dos povos. A escrita ainda ágrafa e pictórica dos egípcios, por exemplo, não reflete de forma alguma uma sociedade primitiva ou atrasada.

Ainda no mesmo capítulo, o autor argumenta que o processo de apropriação e sistematização da escrita representa a ausência (a língua sonoro-visual de outrora era, necessariamente, presencial) e a representação (porque não mais, ao contrário da imitação de outrora, os conceitos precisam ser expressos, mas apenas compreendidos da maneira mais clara possível). Bem entendido, começa a se desvelar a tal expulsão simbólica do Paraíso - portanto, o afastamento não só do homem dos outros homens (para que a voz? Para que o gesto se agora temos a escrita?) como o afastamento do homem da natureza (a representação por convenção).

Ao tratar da prosódia, Rousseau (1781/2008, p. 119 e 122) orienta a diferença entre acento e acentuação.

Se acreditamos em substituir o acento pela acentuação enganamo-nos; somente
inventamos as acentuações quando o acento já foi perdido. [...] Há muita diferença
entre os sinais que determinam o sentido da escrita e os que regulamentam a
pronúncia. Seria fácil criar, apenas com as consoantes, uma língua muito clara quanto
ao escrito, mas que não se poderia falar. A álgebra possui algo dessa língua.

Acento está relacionado à musicalidade original perdida e aos sentimentos que se desejavam transmitir, provocando no ouvinte não o entendimento pela descrição, mas a compreensão viva da coisa-em-si. Ele, o acento, "mente menos" porque é dotado de força expressiva. A acentuação, por sua vez, ferramenta da prosódia, instaura uma artificialidade em que "a voz falante é decomposta num certo número de partes elementares, tanto vocais quanto articuladas, com as quais se possam formar todas as palavras e todas as sílabas imagináveis" (ROUSSEAU, 1781/2008, p. 112).

Os capítulos seguintes (de VI a XI) tratam do processo de aquisição da linguagem nos povos meridionais (quentes e voluptuosos, do apelo "amai-me" nos quais as pessoas vivem) e setentrionais (frios e duros, do apelo "ajudai-me" nos quais as pessoas sobrevivem). Tratam

\section{POLÊM!CA | LABORE}

Polêmica - Revista Eletrônica da Uerj - Rua São Francisco Xavier, 524, $1^{\circ}$ andar bloco D, sl.1001 • Tels.: +55 21 2334-4088/4087 • http://www.e-publicacoes.uerj.br/index.php/polemica/index http://www.labore.uerj.br • laboreuerj@yahoo.com.br 
também das importantes diferenças que a geografia desses povos teve de determinante no caráter dos posteriores idiomas.

A música propriamente dita, figura a partir do capítulo XII. Ressalta-se o argumento do próprio autor porque há a proposta, de maneira sistemática, de uma espécie de revisão conceitual de tudo o que havia sido exposto até então. Segundo Rousseau,

a cadência e os sons nascem com as sílabas: a paixão faz falar todos os órgãos e
confere à voz todo o seu brilho; assim, os versos, os cantos, a palavra, têm uma origem
comum. Ao redor das fontes de que falei, os primeiros discursos foram as primeiras
canções: os retornos periódicos e compassados do ritmo, as inflexões melodiosas dos
acentos, fizeram nascer, com a língua, a poesia e a música, ou melhor, tudo isso não
era outra coisa senão a própria língua para essas felizes regiões e esses felizes tempos
em que as únicas necessidades prementes que exigiam o concurso alheio eram aquelas
que o coração fazia nascer (ROUSSEAU, 1781/2008, p. 145).

Defendendo o paradigma musical como "voz da natureza", Rousseau (2008) vai construindo a ideia do estabelecimento das sociedades, das civilizações, das instituições, da condição humana dentro desse verdadeiro contrato social que ora se configura. Para o autor, a automatização comunicativa da linguagem não só limita (anula?) seu poder de transformação e criação, mas cinde as palavras dos objetos. Isso acontece igualmente entre a palavra e a própria existência, condenando esse homem à solidão "quando novas necessidades, introduzidas entre os homens, forçaram cada um a pensar somente em si mesmo e a fechar seu coração dentro de si” (ROUSSEAU, 1781/2008, p. 138).

Ao abordar a melodia e a harmonia, Rousseau (1781/2008) traça um paralelo entre o acento e a acentuação. A melodia (sentido, contorno e força expressiva do material sonoro), assim como o acento, é um elemento de imitação, ou seja, fornecido e legitimado pela natureza. A harmonia (que exige estudo, treinamento e é convencionalizada), assim como a acentuação, é representativa de uma ação racional cujo propósito seria legitimar o que "soa bem" do que "não soa bem", facilitando o bem ouvir.

Na melodia, assim como na proto-língua-música, estão presentes “todos os sinais vocais das paixões" (ROUSSEAU, 1781/2008, p. 154); era ela o que dotava a palavra de energia. A harmonia, por sua vez, ao estabelecer elementos lógicos de funcionamento, instauraria, verdadeiramente, o começo da degeneração da música. Temos, portanto, um caminho inarredável da história humana que pressupõe "a transposição aberta dos sentidos ao ordenamento fechado do pensamento" (FALABRETTI, 2011, p. 173).

\section{POLÊM!CA | LABORE}

Polêmica - Revista Eletrônica da Uerj - Rua São Francisco Xavier, 524, $1^{\circ}$ andar bloco D, sl.1001 • Tels.: +55 21 2334-4088/4087 • http://www.e-publicacoes.uerj.br/index.php/polemica/index http://www.labore.uerj.br • laboreuerj@yahoo.com.br 
Rousseau (1781/2008) segue propondo ao leitor que pense a respeito da distinção entre a arte musical e a arte pictórica. As cores existem por si, umas independentemente das outras: “O amarelo é amarelo, independentemente do vermelho e do azul; em toda parte ele é sensível e reconhecível" (p. 163); seu efeito é permanente e seu campo de atuação é o espaço.

Os sons não têm, em si, qualquer "caráter absoluto", uma vez que, para conhecer sua natureza, é preciso ter a referência de outros sons (uma nota musical pode, de fato, ser mais grave que algumas e, ao mesmo tempo, mais aguda que outras); seu efeito é temporário e, por isso mesmo, seu campo de atuação é o tempo.

A distinção mais significativa, porém, é a seguinte: enquanto na pintura há uma arte de representação por excelência, na música "pintam-se coisas que não se podem ouvir: o sono, a calma da noite, a solidão e o próprio silêncio entram nas representações da música" (ROUSSEAU, 1781/2008, p. 164). Ao contrário da pintura, portanto, a música não representa diretamente o objeto, mas suscita na alma sensível os mesmos sentimentos que se experimentam ao ver ou estar diante desse mesmo objeto.

Nos capítulos finais da obra, discorre-se a respeito da degeneração da música e da "relação das línguas com os governos" - nos quais o autor, tendo teorizado a respeito da história humana pela linguagem, sai dos domínios da teoria para a vivência social, concreta de sua realidade -. Assim lê-se no Ensaio (ROUSSEAU, 1781/2008, p. 174):

Eis como o canto se tornou, aos poucos, uma arte inteiramente separada da palavra, da qual extrai sua origem; eis como as harmonias do som fizeram com que fossem esquecidas as inflexões da voz e como, enfim, limitada ao efeito puramente físico do concurso das vibrações, a música viu-se privada dos efeitos morais que produzira quando era duplamente a voz da natureza.

A impressão que se tem é a de que, longe de concluir, Rousseau (2008) instiga a reagir diante da brutalidade fria dessa linguagem instrumentalizada e destituída de sua anterior expressividade. É nesse sentido que Freitas $(2008$, p. 18) também convida à seguinte reflexão:

Não é difícil perceber a proximidade da ótica a partir da qual Rousseau concebe o problema da linguagem. A diluição de uma língua na perda de seu potencial expressivo representa para a coletividade a perda de sua própria identidade, uma vez que na língua estão reunidos os caracteres próprios de uma nação. A língua é o modo de expressão por excelência de toda uma cultura, de tal forma que, preservar a integridade da língua é resguardar os valores definidores do corpo social.

\section{POLÊM!CA $\mid$ LABORE}

Polêmica - Revista Eletrônica da Uerj - Rua São Francisco Xavier, 524, $1^{\circ}$ andar bloco D, sl.1001 • Tels.: +55 21 2334-4088/4087 • http://www.e-publicacoes.uerj.br/index.php/polemica/index http://www.labore.uerj.br • laboreuerj@yahoo.com.br 
Ao lado dessa comunicação utilitária e racional, urge a necessidade de buscar formas de expressão que possam dar conta das potencialidades criativas de nós mesmos - o caminho de volta, a contramão. Não é sem razão que o Ensaio ressoa com a proposta defendida de que a música, dispensando a mediação dos conceitos, comunica direta e veementemente nossos afetos. O propalado discurso de que "música é a linguagem das emoções".

$\mathrm{O}$ imediato e a universalidade da linguagem musical podem fazer frente legítima a essa concepção logocênctrica do, segundo Prado Junior (2008), "império do olhar", agindo diretamente sobre os sentimentos que a representação só faz aludir. Seria ela uma aposta necessária, benfazeja subversão.

\section{O Ensaio sobre a origem das línguas e a linguagem musical}

O texto rousseauniano permite uma série de reflexões a respeito dos pressupostos e da atuação de práticas musicais sob outras perspectivas. Se tivermos em mente que, para Rousseau, a linguagem musical é, entre outras coisas, o espaço de resgate do simbólico, compreendemos a importância do fazer musical orientado para a expressão não só de sentimentos e emoções (âmbito subjetivo), como também de uma forma legítima e de suma importância de um funcionamento cognitivo que, por isso mesmo, pode e precisa ser ampliado, treinado, aprimorado. Se a arte, em sua proposta de leitura simbólica da realidade, nos incita à busca de uma visão outra, de um entendimento outro, tanto mais evidente esse processo pode ser encarado na música, dada sua universalidade de manifestação em todas as culturas conhecidas até hoje (LEVITIN, 2006).

A possibilidade de desatar amarras conceituais do signo, ou seja, de prescindir da palavra, da verbalização, pode ser mais que bem-vinda: em muitos casos, aliás, pode ser uma das únicas possibilidades com que o sujeito conta em sua tentativa de manifestar sua expressão - quando se pensa, por exemplo, nas pessoas com deficiências com dificuldades de operacionalizar conceituações abstratas, sem mencionar problemas de ordem motora que dificultam a expressão oral. Comunicar sem abrir a boca. Contar, narrar pelo canto. Apropriarse de uma canção e da segurança de pisar em um terreno já criado pelo intérprete, de trilhar um caminho que já está ali, com seu princípio, desenvolvimento e conclusão. Rodriguez et al. (2015), a esse respeito, propõem uma "revisão narrativa" da literatura relacionada à utilização da música no campo da deficiência intelectual, por exemplo.

\section{POLÊM!CA $\mid$ LABORE}

Polêmica - Revista Eletrônica da Uerj - Rua São Francisco Xavier, 524, $1^{\circ}$ andar bloco D, sl.1001 • Tels.: +55 21 2334-4088/4087 • http://www.e-publicacoes.uerj.br/index.php/polemica/index http://www.labore.uerj.br • laboreuerj@yahoo.com.br 
Com relação ao canto, percebe-se ser esse, provavelmente, o elemento de maior concordância com a teoria rousseauniana: o resgate da palavra revestida de sua musicalidade original. Na verdade, correto seria dizer: o resgate do signo revestido de sua musicalidade original, uma vez que se pode cantar vocalizando, sem, necessariamente, fazer uso da palavra para que isso aconteça.

Mesmo uma vocalização aparentemente aleatória, com sua sucessão de alturas intervalares entre notas, apresenta uma estrutura musical interna que lhe confere o encadeamento de princípio, meio e fim. A esse respeito, Krumhansl (2006, p. 64) advoga que “de todas as dimensões físicas, a altura é talvez a mais diferenciada perceptualmente, a mais elaborada cognitivamente, e aquela sobre a qual mais se teorizou (tanto na música quanto na linguagem)".

Chagas (2001, p. 121) diz que "para eles, o canto é um elemento estruturante do ser humano [...] como um instrumento que habita nossos corpos, faz com que funcionemos como caixas de ressonância, de onde expressamos todo o movimento do que é vitalmente sentido".

Desta forma, pode-se pensar, por exemplo, o quanto a improvisação (compreendida como um gênero musical com um modo de funcionamento peculiar) pode ganhar destaque, uma vez que faz parte de sua natureza a possibilidade da subversão expressiva da comunicação convencionada e delimitante em seu uso cotidiano - sendo, inclusive, uma prática de grandes efeitos na clínica da deficiência (SANTOS, 2017).

A questão que ora se levanta não é tanto sobre a capacidade comunicativa que faz parte da natureza da música e que a pode, inclusive, definir. O propósito aqui é tentar discutir a "gramaticalidade" que caracteriza essa linguagem musical (SLOBODA, 2008). Ou seja, refletir sobre a estrutura que subjaz e define essa forma de arte - assim como a linguagem do signo também apresenta sua estrutura. Além disso, quando se fala em estrutura, há referência a um nível mais profundo, mais basilar, para além de um "comportamento" superficial, indo em direção ao interno, ao constitutivo.

Imbuído da crença de uma universalidade estrutural com relação à linguagem musical, Sloboda (2008, p. 23 e 43) defende que

se a música e a linguagem têm propriedades que demandam gramáticas de uma certa complexidade, então os seres humanos devem possuir recursos psicológicos que permitam representar essas gramáticas. [...] uma vez que a música, assim como a linguagem, é um produto humano, podemos supor, de forma legítima, que a estrutura musical observada nos diz algo sobre a natureza da mente humana que a produz.

\section{POLÊM!CA $\mid$ LABORE}

Polêmica - Revista Eletrônica da Uerj - Rua São Francisco Xavier, 524, $1^{\circ}$ andar bloco D, sl.1001 • Tels.: +55 21 2334-4088 / 4087 • http://www.e-publicacoes.uerj.br/index.php/polemica/index http://www.labore.uerj.br • laboreuerj@yahoo.com.br 
Pelo que foi exposto, perceber como a mente processa a musicalidade, quais os padrões estruturais envolvidos e em que medida essa linguagem se distingue da fala verbalizada, nos permite compreender mais do funcionamento cognitivo de nós mesmos. Quando se encara, por exemplo, a linguagem musical em seu viés terapêutico e promotor de saúde (RUUD, 1991), pode-se constatar sua relevância como agente eficaz de promoção de integração e organização para os sujeitos envolvidos como canal para a "possibilidade de expansão de potencialidades" (TANGARIFE, 1986, p. 46). E isso redimensionando nas pessoas o seu estar no mundo de forma mais criativa, sensível, não-farmacológica e prazerosa. Albornoz (2012, p. 13), aliás, defende que, como recurso terapêutico, a música pode alavancar "uma série de padrões de consciência que conduzem à saúde".

Seguindo com as características entre as linguagens verbal e musical, um importante esclarecimento nesse sentido é dado por Raposo de Medeiros (2006), quando diz que o homem tem capacidades inatas para ambas as linguagens. Provas desse inatismo mencionado seriam, por exemplo, a capacidade que todos têm de identificar uma melodia, de perceber quando um cantor e/ou instrumento desafina, de apreender e reproduzir padrões rítmicos básicos.

Outros pontos em comum dizem respeito à universalidade e, ao mesmo tempo, diversidade de ambas as linguagens: a música, assim como as línguas, são produtos constitutivos da ordenação humana criadas por humanos e para humanos. Ambas as formas de linguagem estão presentes na multiplicidade de variações sociais do mundo - ao mesmo tempo em que marcam fortemente culturas bem definidas: conhecemos um país ou uma região de um país tanto por sua língua (ou dialeto) quanto, também, por sua música.

Como visto anteriormente em Rousseau (1781/2008), o pensador defende a ideia de uma origem comum entre a música e as línguas e o quanto o processo de gramaticalização da fala e harmonização da música comprometeu esse amálgama primordial canto-fala e reconfigurou toda uma forma de organização social.

Tal como a linguagem verbal, a linguagem musical possui pontos específicos mapeados nos lobos cerebrais. Falando especialmente de uma dessas zonas, Levitin (2006, p. 41) nos diz que, de acordo com pesquisas,

a escuta de música conhecida ativa as estruturas neurais profundas, localizadas nas regiões primitivas do cérebro, o vermis cerebelar (cerebellar vermis). Para a música afetar de maneira tão profunda este portal das emoções, a música precisa ter alguma função antiga e importante.

\section{POLÊM!CA | LABORE}

Polêmica - Revista Eletrônica da Uerj - Rua São Francisco Xavier, 524, $1^{\circ}$ andar bloco D, sl.1001 • Tels.: +55 21 2334-4088/4087 • http://www.e-publicacoes.uerj.br/index.php/polemica/index http://www.labore.uerj.br • laboreuerj@yahoo.com.br 
Sobre o referido vermis cerebelar (cerebellar vermis), vale o complemento elucidado por Costa Neto (2013) quando atesta que, ao lado das funções cognitivas, o vermis cerebelar exerce papel importante nas funções emocionais, sendo mesmo um desencadeante do ritmo emocional.

Ainda a respeito das semelhanças entre as linguagens, tanto a linguagem musical quanto a linguagem verbal comunicam conteúdos, podendo, inclusive, admitir múltiplas leituras e/ou apresentar distintos encaminhamentos a depender do contex to cultural em que se manifestem. Além disso, as duas linguagens agem por sequencialidade, criando expectativas tanto quanto ao que virá como quanto ao que se segue: tanto as palavras quanto as notas dispostas em melodia obedecem a uma estrutura sequencial que se queira coerente e compreensível.

As linguagens verbal e musical obedecem a padrões de funcionamento e expressão. Krumhansl (2006, p. 76) afirma que "uma ideia que influencia toda a pesquisa cognitiva em música é que a representação mental da música pelo ouvinte pode ser formalizada mediante um conjunto de regras". A respeito desse conjunto de regras, aliás, André (2017) defende a adaptação e utilização de uma escala específica de comunicabilidade musical ao contexto brasileiro.

Por ser uma capacidade inata, a operacionalização da linguagem verbal e musical advém da assimilação por exposição, uma vez que, desde crianças, apreendemos os padrões de fala e música pelo ouvir e pelo vocalizar - e tanto os falantes quanto poetas e compositores brincam com as possibilidades do discurso, inclusive quebrando, intencionalmente, os padrões convencionais.

A inesgotabilidade entre as linguagens parece ser outro elemento de aproximação: tanto a fala ou verbalização quanto a música podem gerar sequências praticamente ilimitadas de material novo. Pinker (1997 apud MEDEIROS, 2006) fala a respeito da quase infinita capacidade das notas musicais de se combinar em melodias:

\footnotetext{
Não é provável que tenhamos uma escassez de melodias em breve, pois a música é combinatória: se cada nota de uma melodia pode ser selecionada, digamos, de oito notas em média, então existem 64 pares de notas, 512 motivos de três notas, 4096 frases de quatro notas e assim por diante, multiplicando-se em trilhões e trilhões de composições musicais (apud MEDEIROS, 2006, p. 203).
}

Finalmente, pode-se ter em mente que, assim como acontece na linguagem verbal, a linguagem musical igualmente apresenta fonologia, sintaxe e semântica. Sloboda (2008, p. 33)

\section{POLÊM!CA $\mid$ LABORE}

Polêmica - Revista Eletrônica da Uerj - Rua São Francisco Xavier, 524, $1^{\circ}$ andar bloco D, sl.1001 • Tels.: +55 21 2334-4088 / 4087 • http://www.e-publicacoes.uerj.br/index.php/polemica/index http://www.labore.uerj.br・ laboreuerj@yahoo.com.br 
assegura que "assim como o fonema, a nota musical é caracterizada por parâmetros de frequência e duração".

Aquilo que o autor chama de "letramento" da escrita, existe na música e na verbalização e marca uma sintaxe característica, peculiar, referenciada por um encadeamento, uma ordem do que vem antes e depois, construindo uma forma de comunicação que se quer, em princípio, um construto livre de ambiguidades. De acordo com Barcellos (2009, p. 115),

o fato de o discurso musical se desdobrar no tempo e compreender repetições, retornos, preparações, expectativas e resoluções é o que nos leva [...] a falar em narrativa musical. Música e narrativa se desdobram no tempo e têm em comum o aspecto sintático.

Quanto à semântica da música, Sloboda (2008), evoca a possibilidade de, dentro do sistema tonal, associar emoções a "espaços semânticos" específicos por analogia, estabelecendo uma relação tonal das mesmas emoções. A esse respeito, pode-se pensar, por exemplo, na Teoria dos Afetos da música antiga - segundo a qual para cada tonalidade corresponderia uma emoção ou um sentimento específico evocado (GOMES, 2005). Apesar desse processo semântico da música não ser instantâneo e de estar submetido ao contexto cultural no qual se apresenta, fica claro o conteúdo metafórico de que a música pode ser portadora, mesmo não sendo uma linguagem referencial - aliás, justa e exatamente por isso.

De um ponto de vista histórico-evolucionista, ainda Sloboda (2008, p. 50) problematiza uma interessante questão a respeito da diferença fundamental do comportamento entre as linguagens musical e verbal:

\begin{abstract}
A maior parte das pessoas tem à disposição apenas uma língua cuja gramática é bastante estável por períodos longos. [...] ao contrário, as formas e estilos musicais com os quais uma determinada pessoa tem chance de estar familiarizada podem ser bastante diversos. [...] a sintaxe é um veículo para comunicar conhecimento sobre o mundo e, como o mundo segue sendo o mesmo tipo de lugar e como as preocupações humanas continuam as mesmas, há pouco a ganhar e muito a perder com uma diversificação e evolução rápida da sintaxe. A música de arte, ao contrário, não tem uma função tão claramente definida.
\end{abstract}

Eis, enfim, depois de apresentados os argumentos históricos e conceituais defendidos no Ensaio, os pressupostos de aproximação e diferenciação entre as linguagens verbal/escrita e musical.

\title{
POLÊM!CA $\mid$ LABORẸ
}

Polêmica - Revista Eletrônica da Uerj - Rua São Francisco Xavier, 524, $1^{\circ}$ andar bloco D, sl.1001 • Tels.: +55 21 2334-4088/4087 • http://www.e-publicacoes.uerj.br/index.php/polemica/index http://www.labore.uerj.br • laboreuerj@yahoo.com.br 


\section{Considerações finais}

Pensar os aspectos elencados entre a linguagem musical e verbal (similitudes e diferenças) permite repensar ambas as formas de comunicação: manifestação, alcance, propósitos, funcionamento, relações que podem ser estabelecidas. E isso não mencionando que pensar a respeito da linguagem (seja lá como se apresente) é, também, pensar sobre o que nos constitui em nossa humanidade.

O crescente interesse no aspecto especificamente cognitivo musical legitima uma visão, uma crença, de que a música (tocada, escutada, vivida) quase sempre nos coloca em contato com algo em nós mesmos que não pode ser acessado pela via da verbalização - o que nos impele para além da realidade comezinha do cotidiano.

No mito cosmogônico de Gênesis (Cap. 1, 3) (BÍBLIA, 2003), é a voz dO Criador (portanto, o som) o elemento desencadeador da consubstanciação material. A maior referência sobre a qual se assenta o ocidente (independentemente de se acreditar nela ou não) desvela a vibração sonora como formadora de todas as formas.

Novas posturas se fazem necessárias no sentido de estabelecer novos híbridos que, num jogo dinâmico de troca e mútua influência, validem outras propostas de enxergar tanto o funcionamento da comunicação humana no âmbito das linguagens escrita/verbal e musical quanto os sujeitos que delas se utilizam. A Etnomusicologia, a Semiótica Musical, e a Musicoterapia são exemplos dessa conversa.

E isso porque a música, manifestação cultural que é, se encontra presente em todos os ambientes de todas as culturas, sendo, ainda que sem palavras, recurso potente e notavelmente expressivo. Além disso, ela pode ser canal para um texto tecido ao apelo existente na linguagem musical - linguagem que seja acesso a relações múltiplas com outros aspectos dos sujeitos envolvidos em atos de experiências as mais diversas e significativas -. Um apelo que se quer livre de erros e acertos, pautado, entre outras coisas, pela criatividade, prazer e barulho catártico onde, inclusive, as limitações podem ser diluídas.

São de grande valor as palavras de Ruud (1998, p. 9) quando afirma que "escutar música ou tocar um instrumento parece levar para uma consciência de um espaço dentro da própria pessoa que é totalmente distinto e não-acessível aos outros". O fazer musical, bem entendido, como legítima representação do sentido de nós mesmos.

\section{POLÊM!CA $\mid$ LABORE}

Polêmica - Revista Eletrônica da Uerj - Rua São Francisco Xavier, 524, $1^{\circ}$ andar bloco D, sl.1001 • Tels.: +55 21 2334-4088 / 4087 • http://www.e-publicacoes.uerj.br/index.php/polemica/index http://www.labore.uerj.br • laboreuerj@yahoo.com.br 


\section{Referências}

ALBORNOZ, Y. Teoría de Musicoterapia Improvisatoria. Revista Brasileira de Musicoterapia, ano XIV, n. 12, p. 6-17, 2012.

ANDRÉ, A. M. B. Tradução e validação da Escala Nordoff Robins de comunicabilidade musical. 2017. 108f. Dissertação (Mestrado em Música) - Programa de Pós-Graduação em Música, Universidade Federal de Minas Gerais, Belo Horizonte, 2017.

ARISTÓTELES. Política. Tradução, introdução e comentários de Mário da Gama Kury. Brasília, DF: Editora UnB, 1997.

BARCELlOS, L. R. M. A música como metáfora em musicoterapia. 2009. 229f. Tese (Doutorado em Música) - Centro de Artes e Letras, Escola de Música - Instituto Villa-Lobos, Universidade Federal do Estado do Rio de Janeiro, Rio de Janeiro, 2009.

BECHARA, E. Moderna gramática portuguesa. 37. ed. Rio de Janeiro: Nova Fronteira, 2009.

BENENZON, R. Teoria da Musicoterapia: contribuição ao conhecimento do contexto não-verbal. Tradução de Ana Sheila M. de Uricoechea. São Paulo: Summus, 1988.

BÍBLIA, A.T. Gênesis. Português. A Bíblia em ordem cronológica. Nova Versão Internacional. Organização de Edward Reese. Tradução de Judson Canto. São Paulo: Editora Vida, 2003.

BOCK, A. M. et al. Psicologias: uma introdução ao estudo da psicologia. São Paulo: Saraiva, 2001.

CHAGAS, M. Cantar e mover o Som. In: II Fórum Paranaense de Musicoterapia, Encontro Paranaense de Pesquisa em Musicoterapia, Anais... 2001. p. 119-122.

COSTA NETO, J. Efeitos da microinjeção intra vermis cerebelar de tioperamida na consolidação da memória emocional de camundongos. 2013. 55f. Dissertação (Mestrado em Ciências Biológicas) - Centro de Ciências Biológicas e da Saúde, Universidade Federal de São Carlos, São Carlos, 2013.

FALABRETTI, E. A linguística de Rousseau: a estrutura aberta e a potência criadora da linguagem. Analytica, Rio de Janeiro, v. 15, n. 2, p. 147-198, 2011.

FAVERI, C. B. Ensaio sobre a origem das línguas. Tradução de Jean-Jacques Rousseau. Cadernos de Tradução. Florianópolis, v. 2, n. 8, p. 265-271, 2001.

FOUCAULT, M. As palavras e as coisas: uma arqueologia das ciências humanas. Tradução de Salma Tannus Muchail. 8. ed. São Paulo: Martins Fontes, 1999.

FREITAS, J. Linguagem natural e música em Rousseau: a busca da expressividade. Trans/Form/Ação, São Paulo, v. 31, n. 1, p. 53-72, 2008.

GIL, G. Drão. In: Um banda um. Warner Music, 1982. 1 CD. Faixa 7.

GOMES, A. L. Expressão musical no Barroco: a Retórica e a Teoria dos Afetos. 2005. 65 f. Monografia (Graduação em Licenciatura em Música) - Escola de Música, Universidade Estadual de Minas Gerais, Belo Horizonte, 2005.

KRUMHANSL, C. Ritmo e altura na cognição musical. In: ILARI, B. S. (Org.). Em busca da mente musical: ensaios sobre os processos cognitivos em música - da percepção à produção. Curitiba: Editora UFPR, 2006. p. 45-109.

\section{POLÊM!CA $\mid$ LABORE}

Polêmica - Revista Eletrônica da Uerj - Rua São Francisco Xavier, 524, $1^{\circ}$ andar bloco D, sl.1001 • Tels.: +55 21 2334-4088 / 4087 • http://www.e-publicacoes.uerj.br/index.php/polemica/index http://www.labore.uerj.br・ laboreuerj@yahoo.com.br 
LEVITIN, D. Em busca da mente musical. In: ILARI, B. (Org.). Em busca da mente musical: ensaios sobre os processos cognitivos em música - da percepção à produção. Curitiba: Editora UFPR, 2006. p. 23-44.

NEVES, M. H. M. A vertente grega da gramática tradicional: uma visão do pensamento grego sobre a linguagem. São Paulo: Editora UNESP, 2005.

PRADO JUNIOR, B. A força da voz e a violência das coisas. In: ROUSSEAU, J. J. Ensaio sobre a origem das línguas. Tradução de Fúlvia M. L. Moretto. Campinas: Ed. da Unicamp, 2008.

MEDEIROS, B. R. Em busca do som perdido: o que há entre a Linguística e a Música. In: ILARI, B. (Org.). Em busca da mente musical: ensaios sobre os processos cognitivos em música - da percepção à produção. Curitiba: Editora UFPR, 2006. p. 189-227.

RODRIGUES, M. H. C. Gutenberg e o letramento do Ocidente. Revista Educação e Linguagens, Campo Mourão, v. 1, n. 1, p. 188-201, ago./dez. 2012.

RODRIGUEZ, I. A. et. al. A música e a pessoa com deficiência: uma revisão narrativa da literatura. Revista Música e Linguagem, Vitória, v. 1, n. 4, p. 37-51, 2015.

ROUSSEAU, J. J. Discurso sobre a origem e os fundamentos das desigualdades entre os homens. Tradução de Maria Ermantina Galvão. 2. ed. São Paulo: Martins Fontes, 1999.

Emílio ou Da Educação. Tradução de Roberto Leal Ferreira. São Paulo: Martins Fontes, 2004. 2008. Ensaio sobre a origem das línguas. Tradução de Fúlvia M. L. Moretto. Campinas: Ed. da Unicamp,

Do contrato social: princípios do direito político. Tradução de Vicente Sabino Júnior. São Paulo: Editora Pillares, 2013.

Oeuvres complètes: écrits sur la musique, la langue et le théâtre. v. V. Paris: Gallimard, 1995.

RUUD, E. Música e saúde. Tradução de Vera Bloch Wrobel, Glória Paschoal de Camargo, Miriam Goldfeder. São Paulo: Summus, 1991.

Music Therapy: improvisation, communication and culture. Tradução de Eliane Newmeister. Barcelona: Publishers, 1998.

SANTOS, R. L. Música, adultos com deficiências e a expressão de conteúdos internos. 2017. 150 f. Dissertação (Mestrado em Psicologia Clínica) - Departamento de Psicologia - Pontifícia Universidade Católica do Rio de Janeiro, Rio de Janeiro, 2017.

SLOBODA, J. A mente musical: psicologia cognitiva da música. Tradução de Beatriz Ilari e Rodolfo Ilari. Londrina: EDUEL, 2008.

TANGARIFE, A. S. Musicoterapia e deficiência mental: teorias e técnicas. Sociedade Pestalozzi do Brasil, Rio de Janeiro, Boletim 59/60, p. 33-60, 1986.

VALLE, L. Linguagem e formação humana. Terceira Margem, Rio de Janeiro, v. 25, p. 55-72, 2011.

Recebido em: 01/12/2018.

Aceito em: 30/12/2018.

\section{POLÊM!CA $\mid$ LABORE}

Polêmica - Revista Eletrônica da Uerj - Rua São Francisco Xavier, 524, $1^{\circ}$ andar bloco D, sl.1001 • Tels.: +55 21 2334-4088 / 4087 • http://www.e-publicacoes.uerj.br/index.php/polemica/index http://www.labore.uerj.br・ laboreuerj@yahoo.com.br 